\title{
Effects of silencing endothelin-1 on invasion and vascular formation in lung cancer
}

\author{
ZHEN-YU ZHANG, LI-LI CHEN, WEI XU, KESHAVRAJ SIGDEL and XING-TANG JIANG
}

Department of Respiratory Medicine, Zhongshan Hospital Affiliated to Xiamen University, Xiamen, Fujian 361004, P.R. China

Received June 11, 2015; Accepted February 27, 2017

DOI: $10.3892 / 01.2017 .6027$

\begin{abstract}
Endothelin-1 (ET-1), which exists not only in the vascular endothelium but is also widely present in various tissues and cells, is an important cardiovascular regulatory factor that serves an important role in maintaining the basal vascular tone and homeostasis in the cardiovascular system. In the present study, the ET-1 gene was silenced by RNA interference, and the effects on lung cancer cell proliferation and tumor cell invasion were then detected by Cell Counting kit- 8 and Transwell assays. In addition, the expression of apoptosis, growth and invasion-associated proteins, including RhoA/C, vascular endothelial growth factor, pigment epithelium-derived factor, AKT, E-cadherin and cyclooxygenase- 2 was evaluated by western blotting upon silencing ET-1. In the present study, Endostar, a recombinant human endostatin injectable drug, was also used, and it was assessed whether the sensitivity of tumor cells to this drug could be increased by silencing ET-1. Both in vivo and in vivo tests were carried out in the present study. The experimental data indicated that ET-1 silencing can inhibit tumor cell proliferation and invasion, particularly in the presence of Endostar.
\end{abstract}

\section{Introduction}

Lung cancer is one of the most common malignant tumors and health hazards worldwide. It is also one of the world's fastest rising cancers in terms of morbidity and mortality (1). The majority of lung cancer patients present with a late-stage disease when they are diagnosed, which is not curable by current therapies. Cancer is an extremely complex process, and a variety of genes are involved in the completion of this multi-step process (2). Preventing the invasion and metastasis of lung cancer, which affects failure treatment and mortality in patients with lung cancer, is currently the key to the treatment

Correspondence to: Professor Xing-Tang Jiang, Department of Respiratory Medicine, Zhongshan Hospital Affiliated to Xiamen University, 201 Hubin South Road, Xiamen, Fujian 361004, P.R. China

E-mail: xmzsjxt@163.com

Key words: endothelin-1, A549, proliferation, invasion, Endostar of lung cancer (3). Despite the fact that numerous novel therapeutic interventions have been performed, lung cancer remains a serious healthcare problem, and its incidence and mortality have continuously increased during the last decade (4). Therefore, an effective and safe method for the treatment of lung cancer is required.

Endothelins (ETs), a class of peptides produced by endothelial cells, have a strong vasoconstrictor effect (5). ETs are composed of 21 amino acids, and four isomers (peptide isoforms), namely ET-1, ET-2, ET-3 and ET-4, have been identified in the ET family (6). Since their discovery by Yanagisawa et al in 1988 (7), multiple studies have demonstrated that ETs not only are able to strengthen the contraction of vascular and cardiac muscle as well as promote the neuroendocrine function, but are also powerful pro-growth and cell differentiation factors (8). ETs have a cell growth factor-like effect that can promote DNA synthesis, proto-oncogene expression and cell proliferation. In addition, ETs can induce angiogenesis during tumor growth (6). At present, the majority of studies focus on ET-1 due to its strong biological activity (9). ETs serve an important role in the development of tumors, since they can activate proto-oncogenic genes as well as promote cell division and proliferation in collaboration with other growth factors (10). In addition, the activation of oncogenes mediated by ETs promotes cell proliferation and serves an important role in the development of tumors (6). ET-1 can promote tumor angiogenesis directly or indirectly via the paracrine route (11). Previous studies have shown that ET-1 is highly expressed in lung cancer and is involved in lung cancer cell proliferation (12). However, the association between ETs and tumors' growth and metastasis has not been fully clarified yet.

Endostar, a modified recombinant human endostatin, demonstrated a better effect on vasoconstrictivity than endostatin, and has been widely studied for the treatment of diseases caused by pathological angiogenesis (13). Extensive studies revealed that Endostar significantly inhibited cell proliferation, migration and invasion in a dose-dependent manner (13). Thus, in the present study, Endostar was used as a positive control drug during the experiments.

In the present study, ET-1 was silenced via RNA interference (RNAi), and the proliferation of A549 cells and the expression of apoptosis, growth and invasion-associated factors, including RhoA/C, vascular endothelial growth factor (VEGF), pigment epithelium-derived factor (PEDF), AKT, 
E-cadherin and cyclooxygenase (Cox)-2, were then examined. It was observed that ET-1 RNAi can inhibit A549 cells proliferation and invasion more effectively than Endostar, which suggested that ET-1 RNAi may be a new effective strategy to treat lung cancer.

\section{Materials and methods}

Cell culture. The A549 cell line used in the present study was purchased from the American Type Culture Collection (Manassas, VA, USA) and was maintained in Dulbecco's modified Eagle's medium (DMEM; Gibco; Thermo Fisher Scientific, Inc., Waltham, MA, USA) with $10 \%$ fetal bovine serum (FBS; Gibco; Thermo Fisher Scientific, Inc.) at $37^{\circ} \mathrm{C}$ and $5 \% \mathrm{CO}_{2}$.

ET-1 short hairpin RNA (shRNA) construction. The shRNAs targeting three positions of the human ET-1 gene (1, 5'-CCA TGAGAAACAGCGTCAA-3'; 2, 5'-AAGGCAACAGACCGT GAAA-3'; and 3, 5'-TGCCAATGTGCTAGCCAAA-3') were designed by Sangon Biotech Co., Ltd. (Shanghai, China). The synthesized shRNAs were then ligated into the pCMV-G\&NR vector (Sangon Biotech Co., Ltd.), giving rise to the different pCMV-G\&NR-ET-shRNA constructs. The constructs were then transfected into A549 cells using Lipofectamine 2000 (Invitrogen; Thermo Fisher Scientific, Inc.) according to the manufacturer's protocol. The transfection efficiency was determined by fluorescence microscopy (Olympus Corporation, Tokyo, Japan).

Reverse transcription (RT)-quantitative polymerase chain reaction $(P C R)$. Total RNA was extracted using TRIzol reagent (Invitrogen; Thermo Fisher Scientific, Inc.), and the integrity of RNA was analyzed by $1 \%$ agarose gel electrophoresis (Bio-Rad Laboratories, Inc., Hercules, CA, USA). Gels were visualized using the Gel Imaging and Analysis System (Syngene, Frederick, MD, USA). High Capacity cDNA Reverse Transcription kit (Thermo Fisher Scientific, Inc.) was used for the RT step, and SYBR Green PCR Master Mix kit (Thermo Fisher Scientific, Inc.) was used for the amplification step. The sequences of the primers for ET-1 and GAPDH were as follows: ET-1 forward (F), 5'-GCCTGTCTGAAGCCA TAG-3' and reverse (R), 5'-GCTGAGAGGTCCATTGTC-3'; and GAPDH F, 5'-CACCCACTCCTCCACCTTTG-3' and R, 5'-CCACCACCCTGTTGCTGTAG-3'. The following PCR conditions were used: $95^{\circ} \mathrm{C}$ for $10 \mathrm{~min}$, followed by 40 cycles of $95^{\circ} \mathrm{C}$ for $15 \mathrm{sec}$ and $60^{\circ} \mathrm{C}$ for $45 \mathrm{sec}$. The messenger RNA (mRNA) level was analyzed by ABI 7300 Real-Time PCR System (Applied Biosystems; Thermo Fisher Scientific, Inc.). The results were analyzed by ABI Prism 7300 SDS software version 1.4 (Applied Biosystems; Thermo Fisher Scientific, Inc.).

Cell proliferation assay. Cell Counting kit (CKK)-8 assay (Beyotime Institute of Biotechnology, Haimen, China) was used to detect cell proliferation according to the manufacturer's protocol. A549 cells were plated at a density of 2,000 cells/well onto 96 -well plates. Upon incubation, $10 \mu 1$ CKK-8 reagent was added to the plates, which were then incubated at $37^{\circ} \mathrm{C}$ for $4 \mathrm{~h}$. Next, absorbance at $450 \mathrm{~nm}$ was measured using a microplate reader (Bio-Rad Laboratories, Inc.).

Invasion detection. Invasion assay was performed using Transwell inserts (EMD Millipore, Billerica, MA, USA) to test the invasion of A549 cells subjected to different treatments. The upper well of the Transwell (Corning Inc., Corning, NY, USA) was coated with Matrigel (BD Biosciences, Franklin Lakes, NJ, USA) and incubated at $37^{\circ} \mathrm{C}$ in a $5 \% \mathrm{CO}_{2}$ for $1 \mathrm{~h}$. The indicated cells were serum starved for $24 \mathrm{~h}$. Subsequently, $5 \times 10^{4}$ cells in $500 \mu \mathrm{l}$ serum-free DMEM were seeded into the upper well of the Transwell chamber. Culture medium, supplemented with $10 \%$ FBS $(750 \mu \mathrm{l})$ was added into the lower well of the chamber. After $48 \mathrm{~h}$ incubation, the cells in the upper well were removed with a cotton swab and the cells that migrated into the lower well were washed with PBS, fixed in $3.7 \%$ paraformaldehyde and stained with $0.2 \%$ crystal violet. Images of the cells were captured and cell number was counted using an Olympus CX41RF microscope (Olympus Corporation). The number of cells that traversed the filter was detected by staining with crystal violet.

Western blotting. Cells were harvested and washed twice with PBS, and then lysed for $10 \mathrm{~min}$ in a lysis buffer (Beyotime Institute of Biotechnology) at $4^{\circ} \mathrm{C}$. Upon centrifugation $\left(12,000 \mathrm{x} \mathrm{g}, 10 \mathrm{~min}\right.$ at $\left.25^{\circ} \mathrm{C}\right)$, the protein concentration was determined using Pierce BCA Protein Assay kit (Thermo Fisher Scientific, Inc.). Proteins were separated by $10 \%$ SDS-PAGE and electroblotted onto Immobilon polyvinylidene difluoride membranes (EMD Millipore). The membranes were then blocked with fat-free milk overnight at $4^{\circ} \mathrm{C}$, and incubated with primary antibodies over night at $4^{\circ} \mathrm{C}$. Primary antibodies against VEGF (ab46154), PEDF (ab115489), RhoC (ab54837) and Cox-2 (ab15191) were purchased from Abcam (Cambridge, MA, USA). Primary antibodies against E-cadherin (Sc-9989) and RhoA (Sc-179) were purchased from Santa Cruz Biotechnology, Inc. (Dallas, TX, USA), while antibodies for AKT (9272S), phosphorylated (p)-AKT (4058S) and GAPDH (5471) were purchased from CST Biological Reagents Co., Ltd. (Shanghai, China). The dilutions of the antibodies were as follows: Anti-VEGF, 1:1,000; anti-PEDF, 1:1,000; anti-AKT, 1:1,000; anti-p-AKT, 1:1,000; anti-RhoC, 1:500; anti-Cox-2, 1:400; anti-E-cadherin, 1:100; anti-RhoA, 1:100; and anti-GAPDH, 1:1,500. The secondary antibodies anti-rabbit immunoglobulin (Ig)G (A0208; 1:1,000; Beyotime Institute of Biotechnology) and anti-mouse IgG (A0216; 1:1,000; Beyotime Institute of Biotechnology) were used to detect the primary antibodies. Membranes were incubated with secondary antibodies for $1 \mathrm{~h}$ at $37^{\circ} \mathrm{C}$, and visualized with enhanced chemiluminescence (EMD Millipore) according to the manufacturer's protocol. Signals were quantified by densitometry (Quantity One software, version 4.62; Bio-Rad Laboratories, Inc.). GAPDH was used as a control.

In vivo tumor-inhibitory experiments. A total of $12 \mathrm{BALB} / \mathrm{c}$ male nude mice (4-5 weeks of age and $20 \mathrm{~g}$ of weight; housed at $25^{\circ} \mathrm{C}$ on a $12 \mathrm{~h} \mathrm{light/dark} \mathrm{cycle,} \mathrm{with} \mathrm{access} \mathrm{to} \mathrm{food} \mathrm{and}$ water ad libitum) were purchased from the Second Military Medical University (Shanghai, China) and were randomly divided into two groups (6 mice/group). In total, 6 nude mice 
A

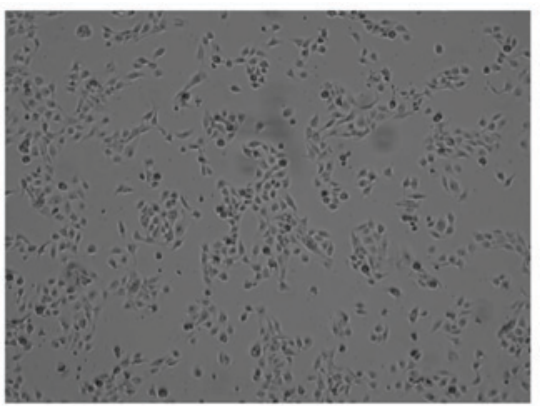

C

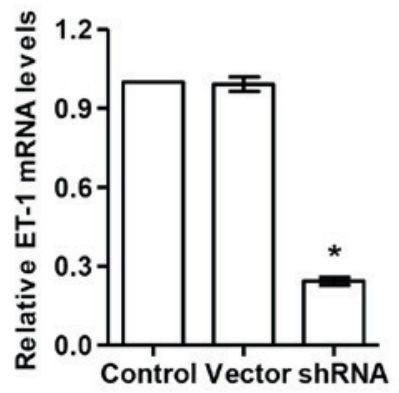

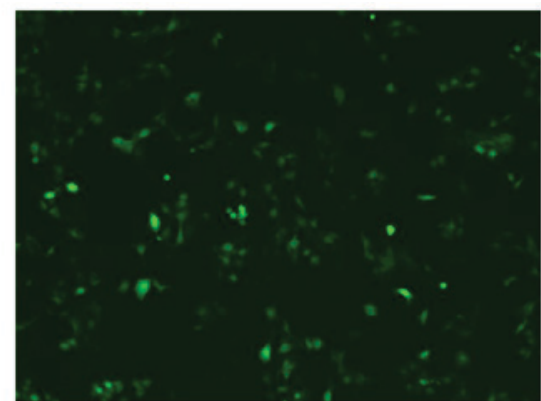

D

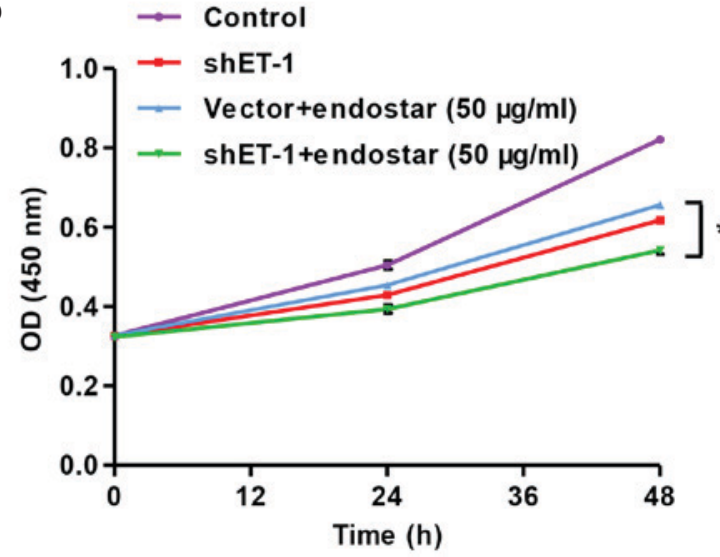

Figure 1. shRNA ET-1 was successfully transfected into A549 Cells. (A and B) To evaluate the transfection efficiency, the reporter gene enhanced green fluorescent protein was observed under (A) white light and (B) green fluorescence (magnification, x100). (C) The expression of shRNA ET-1 in A549 cells was determined by reverse transcription-quantitative polymerase chain reaction. Data are presented as the mean $\pm \mathrm{SD}, \mathrm{n}=3$. ${ }^{*} \mathrm{P}<0.05$ compared with the vector group. (D) The proliferation of different groups of A549 cells was detected by Cell Counting kit- 8 assay. Data are presented as the mean \pm SD, $n=3$. * $<0.05$ compared with the vector group. sh, short hairpin; ET, endothelin; mRNA, messenger RNA; SD, standard deviation.

were injected subcutaneously with vector-transfected A549 cells $\left(2 \times 10^{6}\right)$, while another 6 mice were injected subcutaneously with ET-1-silenced A549 cells $\left(2 \times 10^{6}\right)$. The tumors were formed 1-2 weeks later, and the tumor size was determined every 3-4 days after tumor formation. Tumor volume (V) was measured and calculated using the following formula: $\mathrm{V}\left(\mathrm{mm}^{3}\right)=0.5 \mathrm{x}$ larger diameter $\mathrm{x}$ smaller diameter ${ }^{2}$. At 43 days following injection, nude mice were sacrificed following cervical dislocation. Once the nude mice were sacrificed, the tumors were dissected and their weights were measured. The experiment was performed under the Zhongshan Hospital Affiliated to Xiamen University's (Xiamen, China) guidelines for animal experiments. The study was approved by the ethics committee of Zhongshan Hospital Affiliated to Xiamen University.

Statistical analyses. All data are presented as the mean \pm standard deviation of at least three experiments. Statistical significance was determined by analysis of variance using SPSS 17.0 software (SPSS, Inc., Chicago, IL, USA). P<0.05 was considered to indicate a statistically significant difference.

\section{Results}

Establishment of shET-1 A549 cells. To investigate the function of ET-1 in lung cancer, the expression of ET-1 was suppressed by RNAi in A549 cells. Three shRNAs targeting human ET-1 were designed, cloned into the pCMV-G\&NR vector and transfected into A549 cells. The transfection efficiency
A
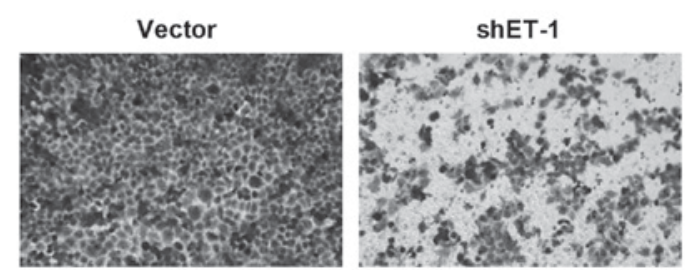

Vector+endostar

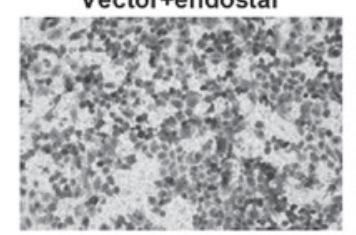

ShET-1+endostar

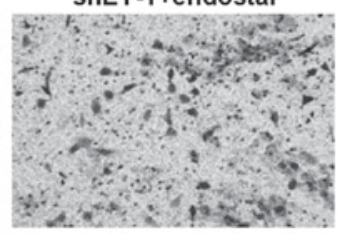

$\mathbf{B}$

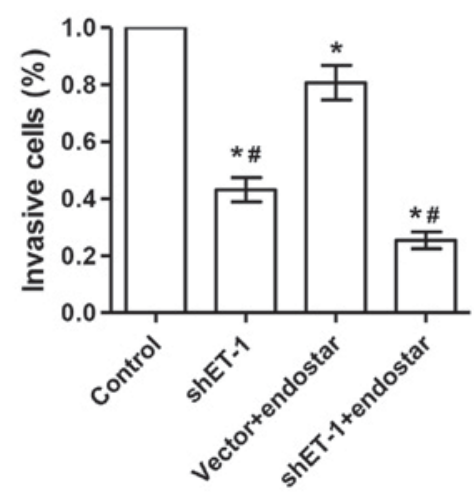

Figure 2. (A and B) Invasion of A549 cells subjected to different treatments. Data are presented as the mean \pm standard deviation, $n=3$. ${ }^{*} \mathrm{P}<0.05$ compared with the vector group; ${ }^{\#} \mathrm{P}<0.05$ compared with the vector + Endostar group. sh, short hairpin; ET, endothelin. 


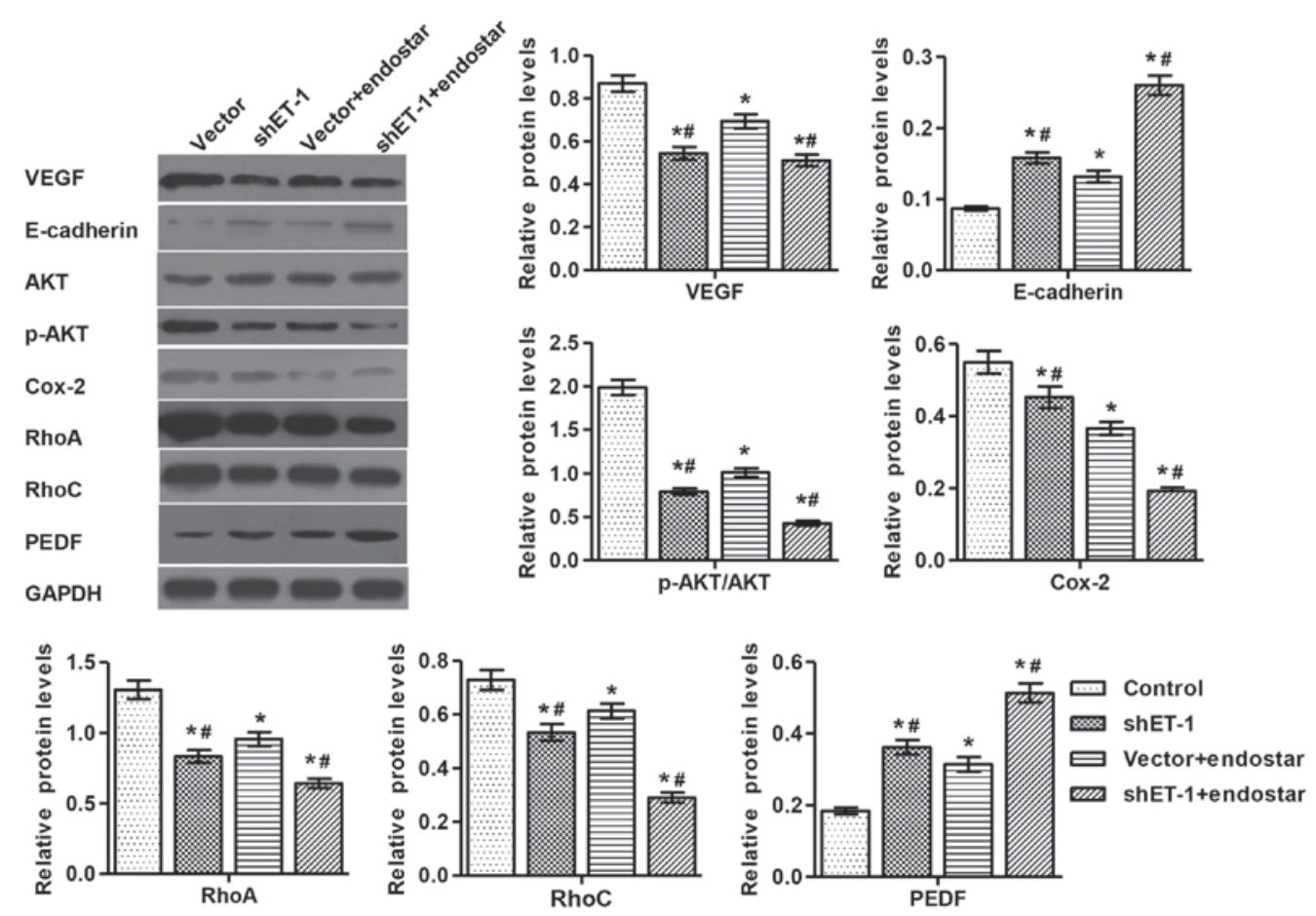

Figure 3. Relative protein expression, as detected by western blotting after treatment for $48 \mathrm{~h}$. Data are presented as the mean \pm standard deviation, $\mathrm{n}=3$. ${ }^{*} \mathrm{P}<0.05$ compared with the vector group; ${ }^{\#} \mathrm{P}<0.05$ compared with the vector + Endostar group. VEGF, vascular endothelial growth factor; p, phosphorylated; Cox, cyclooxygenase; PEDF, pigment epithelium-derived factor; sh, short hairpin; ET, endothelin.
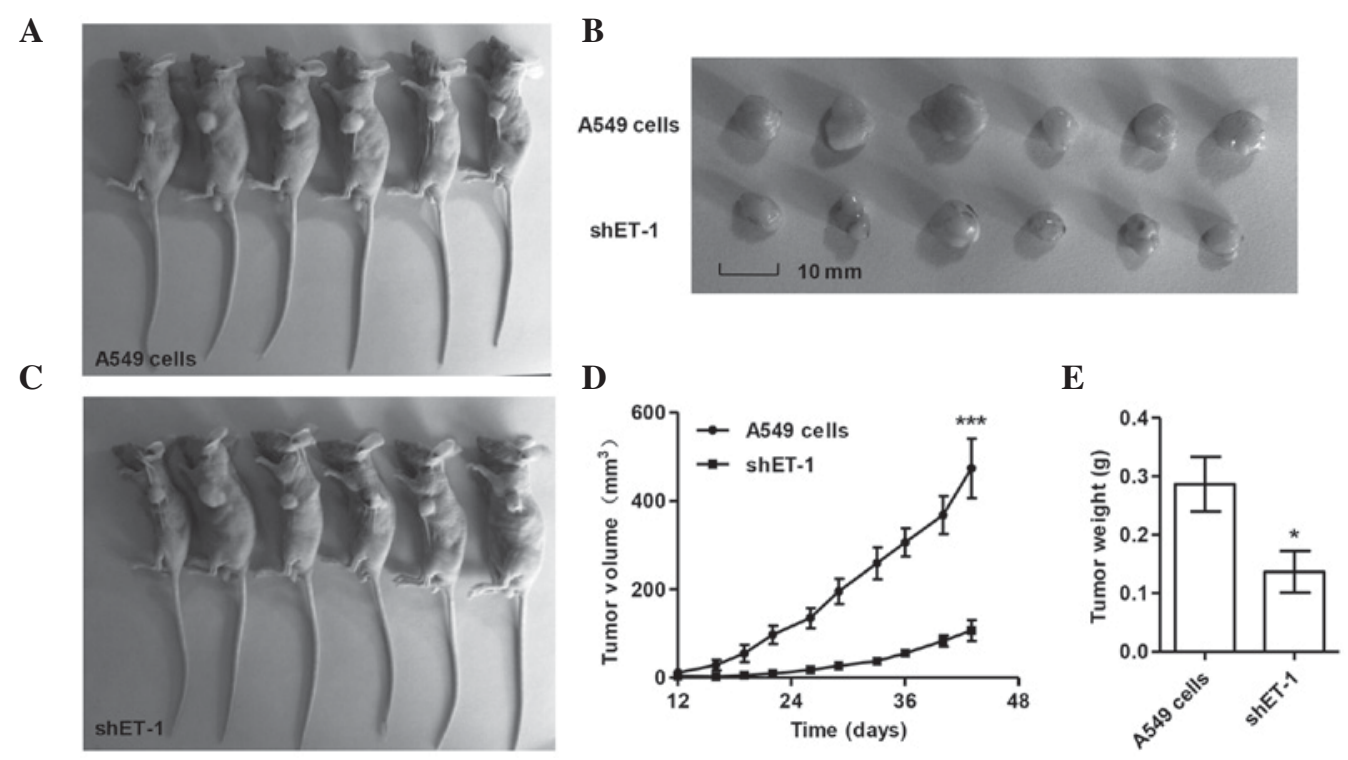

Figure 4. Effect of ET-1 RNA interference in vivo. (A) Mice injected with empty vector. (B) Tumor volume was measured. (C) Mice injected with ET-1-silenced A549 cells. (D and E) Tumors were dissected, and their (D) volume and (E) weight were measured with a vernier caliper. ${ }^{* * * *} \mathrm{P}<0.001$, ${ }^{*} \mathrm{P}<0.05$ compared with A549 cells. sh, short hairpin; ET, endothelin.

was 53\% (transfection efficiency $=$ number of cells with green fluorescence/total cells), as evaluated by fluorescence microscopy (Fig. 1A and B). The third fragment, 5'-TGCCAA TGTGCTAGCCAAA-3' (targeting position 321-339), was the most efficient shRNA for silencing ET-1 (Fig. 1C). shRNAs 1,2 and 3 significantly decreased mRNA expression of ET-1 by $35.0,42.8$ and $75.4 \%$, respectively. These data suggested that the shRNAs designed in the present study had a significant interference effect on the expression of ET-1, and that
ET-1-silenced A549 cells (transfected with shRNA 3) were successfully established and could be used for further analysis.

Effect of ET-1 RNAi on the proliferation of A549 cells. To determine the effects of ET-1 RNAi with/without Endostar on the proliferation capability of A549 cells, CCK-8 assay was performed. The results of CCK-8 assay (Fig. 1D) revealed that both Endostar and ET-1 RNAi could suppress the proliferation of A549 cells. In addition, the combined use of Endostar and 
ET-1 shRNA exhibited a stronger inhibition of the proliferation of A549 cells compared with that caused by Endostar or ET-1 shRNA separately $(\mathrm{P}<0.05)$. These results indicated that the downregulation of ET-1 can decrease the growth capacity of A549 cells, and such effect can be augmented by Endostar treatment.

The invasive ability of A549 cells is suppressed by ET-1 RNAi. Invasive capacity is essential for the malignant biological behavior of tumors. The present study investigated whether ET-1 RNAi affected the invasive ability of A549 cells. In contrast to control cells, ET-1 RNAi and Endostar could significantly reduce the cell invasive ability of A549 cells. The number of invaded cells in the ET-1 shRNA + Endostar group was significantly decreased compared with that in the ET-1 shRNA or Endostar groups $(\mathrm{P}<0.05)$ (Fig. 2). The results indicated that the downregulation of ET-1 decreased the invasive ability of A549 cells, which could be potentiated by Endostar treatment. In addition, the expression of RhoA/C, VEGF, PEDF, AKT, E-cadherin and Cox-2 proteins was detected by western blotting (Fig. 3).

Inhibitory effect of ET-1 RNAi on the growth of human lung carcinoma xenografts in nude mice. Next, it was determined whether knocking down ET-1 in lung cancer cells could reduce tumor growth in vivo. A549 cells transfected with control or ET-1-shRNA were subcutaneously injected in athymic nude mice, and tumor volumes were measured for 45 days. As shown in Fig. 4, the ET-1-shRNA-treated tumors grew slower than the control tumors $(\mathrm{P}<0.05)$. These data indicated that ET-1 RNAi can effectively inhibit tumor growth in vivo.

\section{Discussion}

Despite the fact that numerous novel therapeutic interventions have been performed, lung cancer remains a serious healthcare problem (3). The growth, division and DNA synthesis of normal lung cells are regulated through the orderly cell cycle. If this order is disrupted, tumors may be eventually induced (14). In addition, the invasion and metastasis of lung cancer are extremely complex processes, where multiple genes and steps are involved (15). Lung cancer invasion and metastasis seriously affect the efficacy and prognosis of patients with cancer who are undergoing treatment, and are also the main causes of patients' treatment failure and mortality. Therefore, preventing the invasion and metastasis of lung cancer is currently key in lung cancer treatment. At present, a great progress has been achieved for the prevention and treatment of early lung cancer; however, the treatment effect and prognosis remain poor (3). Thus, to prevent and cure lung cancer, tumor pathogenesis must be further explored, and more effective targeted therapies must be developed.

Since ETs were identified, it has been verified that ETs not only perform the function of vasoconstriction, but are also closely connected with the growth of tumors. Numerous studies conducted on different types of tumor tissue, observed that ETs exist in malignant tumor tissues $(8,16)$. Furthermore, ET-1 levels in plasma exhibited a visible difference prior and subsequent to treatment, and ET-1 content was significantly decreased following treatment (17). In addition, previous studies have suggested that ETs can activate proto-oncogenic genes, promote cell division and proliferation in collaboration with other growth factors, and serve an important role in the development of tumors. In recent years, the association between ETs and tumor growth and metastasis is receiving great attention, but this association has not been fully elucidated yet.

The present study detected VEGF, PEDF, Cox-2, AKT, p-AKT, E-cadherin, RhoA and RhoC, which are associated with tumor apoptosis, growth, invasion and metastasis (18-20). The results revealed that the expression of all the above factors was increased or decreased when shET-1 and Endostar were present or absent. In the current study, the expression of VEGF was decreased when ET-1 was silenced. VEGF is the most effective pro-angiogenic growth factor, and serves an important role in cancer angiogenesis, tumor growth and metastasis. ET-1 can promote the processes of invasion and metastasis via activation of hypoxia-inducible factor- $1 \alpha$ and VEGF in melanoma. Melanoma can also promote the expression of VEGF mRNA and the secretion of VEGF via ET-1. Thus, there is an indirect synergism between ET-1 and VEGF $(21,22)$. Matsuura et al (23) indicated that mutual stimulation of ET-1 and VEGF resulted in increased endothelial cell proliferation, migration and invasion of the basement membrane, suggesting that ET-1 induced endothelial cell proliferation, invasion and tumor angiogenesis through stimulation of the secretion of VEGF (24). That study confirmed that ET-1 stimulates the secretion of VEGF and endothelial cell proliferation, invasion which induced by VEGF, and indirectly effects on tumor angiogenesis and provides a microenvironment for tumor growth (24). The present results are consistent with those from previous studies.

E-cadherin serves an important role in selective cell aggregation. Previous studies have shown that ET-1 can reduce the expression of E-cadherin, and influence the invasion and metastasis of tumors (25). In the present study, E-cadherin was increased in the ET-1 RNAi group, which suggested that ET-1 RNAi could promote the invasion of lung cancer. The serine/threonine protein kinase AKT and activated AKT, which is phosphorylated, are important in regulating apoptosis, angiogenesis and the cell cycle (26-28). Generally, the extent of activation of the PI3K/AKT signaling pathway is determined based on the phosphorylation level of AKT, which is a key signaling protein in the PI3K signaling pathway $(26,29,30)$. It has been reported that the apoptosis of ovarian carcinoma cells induced by paclitaxel can be reverted by ET-1 through upregulating the activity of AKT (31). As a synthesis rate-limiting enzyme of prostaglandin (PG), which is an important inflammatory mediator, Cox-2 can reduce endothelial cell apoptosis (32). Despite the fact that Cox-2 cannot be detected in the majority of normal tissues and cells, when an inflammatory response happens in vascular endothelial and smooth muscle cells, Cox- 2 may be induced by cytokines, ETs and PGs (33). Cox-2 participates in a variety of pathological and physiological processes. Cox-2 induces tumor angiogenesis and invasion by promoting cell proliferation and inhibiting cell apoptosis, thus participating in the development of tumors $(34,35)$. Previous studies have reported that Cox-2 can induce the expression of several vascular factors such as ET-1 and transforming growth factor- $\beta$, while ET-1 can also 
upregulate Cox-2 expression. Thereby, it forms a positive feedback network, which could co-stimulate tumor angiogenesis (36). In the present study, p-Akt/Akt and Cox-2 expression exhibited a decreased trend when ET-1 was silenced. All these data suggested that the interference of ET-1 was effective for the treatment of lung cancer.

Rho is a type of guanosine-5'-triphosphate (GTP)-binding protein with GTPase enzymatic activity. Rho has been associated with tumorigenesis, invasion and metastasis, and has been observed to exhibit a high expression in malignancy (37). Previous studies suggested that the RhoC gene was involved in the occurrence and development of liver cancer, and that a close association existed between the high expression of $\mathrm{RhoC}$ and the phenotype of hepatocellular carcinoma regarding cell invasion and metastasis (38). Previous studies demonstrated that RhoA/C was highly expressed in a variety of malignancies, participated in the adhesion and migration of tumor cells, and markedly promoted the occurrence and development of tumors (39-42). As a novel tumor marker, Rho can be applied to distinguish between benign and malignant lesions, and may help to assess the ability of tumor metastasis and prognosis (43). This has potentially important clinical value for cancer prevention. Rho was observed to participate in the movement and angiogenesis of endothelial cells induced by VEGF through Rho-associated protein kinase signal transduction pathways, thus promoting tumor angiogenesis and assisting tumor cells to establish distant metastases through the vascular endothelia (44). Previous studies speculated that a potential mechanism to inhibit tumor angiogenesis may be to inhibit VEGF expression by enhancing P53 (a tumor-suppressor gene) expression (45). Other studies indicated that Rho protein was involved in regulating tumor angiogenesis (46). A study has revealed that there are complex interactions between Rho protein and E-cadherin (47). Overexpression of Rho proteins may promote the metastasis of tumor cells through undermining intercellular adhesion (48). The present study noticed that RhoA/C was expressed at lower levels in the ET-1 RNAi group than in the empty vector group. Thus, it could be speculated that ET-1 RNAi can inhibit the expression of RhoA/C. However, the mechanism involved remains unclear.

The present data also revealed that the PEDF level was decreased when ET-1 RNAi was applied to A549 cells. PEDF was an effective factor in inhibiting angiogenesis, having a neuroprotective effect, inducing tumor apoptosis, and inhibiting tumor cells invasion and metastasis. However, it has been demonstrated that PEDF cannot affect the AKT signaling pathway (49). Mahtabifard et al (50) reported that PEDF can inhibit angiogenesis in breast cancer. Takenaka et al (51) reported that PEDF can induce the apoptosis of MG63 (osteosarcoma cells) and inhibit the expression of VEGF, thus inhibiting tumor angiogenesis. Zhang et al (52) reported that PEDF expression was decreased in non-small cell lung cancer. PEDF level is inversely proportional to microvessel density in tumor tissue, and PEDF mRNA level is inversely proportional to the size of the tumor. The low level of PEDF in lung cancer suggests a poor prognosis $(53,54)$. Abe et al (55) reported that PEDF serves an important role in inhibiting tumor proliferation and tumor angiogenesis processes, and deletion of the PEDF gene may be associated with the malignant differentiation of normal cells. However, the association between malignant tumors and the PEDF gene remains unclear.

Although there are no studies indicating that Rho and PEDF have any direct connection with ET-1, it can be speculated that Rho and PEDF may be indirectly regulated in the present study. Compared with their expression in the vector group, the expression of the tumor-associated factors examined in the present study exhibited significant changes. These results indicated that ET-1 RNAi may have a potential therapeutic effect on the treatment of lung cancer. Furthermore, it was observed that the therapeutic effect was improved when both ET-1 RNAi and Endostar acted on the cells, and this result was also verified in in vivo experiments.

\section{References}

1. Stanzani F, de Moraes Paisani D, de Oliveira A, de Souza RC, Perfeito JAJ and Faresin SM: Morbidity, mortality, and categorization of the risk of perioperative complications in lung cancer patients. J Bras Pneumol 40: 21-19, 2014.

2. Wong YH, Chen RH and Chen BS: Core and specific network markers of carcinogenesis from multiple cancer samples. J Theor Biol 362: 17-34, 2014.

3. Reno TA, Kim JY and Raz DJ: Triptolide inhibits lung cancer cell migration, invasion, and metastasis. Ann Thorac Surg 100: 1917-1824, 2015.

4. Justilien V and Fields AP: Utility and applications of orthotopic models of human non-small cell lung cancer (NSCLC) for the evaluation of novel and emerging cancer therapeutics. Curr Protoc Pharmacol 62: 14.27.1-14.27.17, 2013.

5. Feldstein $\mathrm{C}$ and Romero $\mathrm{C}$ : Role of endothelins in hypertension. Am J Ther 14: 147-153, 2007

6. Hynynen MM and Khalil RA: The vascular endothelin system in hypertension-recent patents and discoveries. Recent Pat Cardiov Drug Discov 1: 95, 2006.

7. Yanagisawa M, Kurihara H, Kimura S, Tomobe Y, Kobayashi M, Mitsui Y, Yazaki Y, Goto K and Masaki T: A novel potent vasoconstrictor peptide produced by vascular endothelial cells. Nature 332: 411-415, 1988.

8. Dworkin S, Simkin J, Darido C, Partridge DD, Georgy SR, Caddy J, Wilanowski T, Lieschke GJ, Doggett K, Heath JK and Jane SM: Grainyhead-like 3 regulation of endothelin-1 in the pharyngeal endoderm is critical for growth and development of the craniofacial skeleton. Mech Dev 133: 77-90, 2014.

9. Grimshaw MJ: Endothelins and hypoxia-inducible factor in cancer. Endocr Relat Cancer 14: 233-244, 2007.

10. Schrey MP, Patel KV and Tezapsidis N: Bombesin and glucocorticoids stimulate human breast cancer cells to produce endothelin, a paracrine mitogen for breast stromal cells. Cancer Res 52: 1786-1790, 1992.

11. Knowles J, Loizidou M and Taylor I: Endothelin-1 and angiogenesis in cancer. Curr Vasc Pharmacol 3: 309-314, 2005.

12. Zhang WM, Zhou J and Ye QJ: Endothelin-1 enhances proliferation of lung cancer cells by increasing intracellular free $\mathrm{Ca}^{+}$. Life Sci 82: 764-771, 2008.

13. Xu X, Mao W, Chen Q, Zhuang Q, Wang L, Dai J, Wang H and Huang Z: Endostar, a modified recombinant human endostatin, suppresses angiogenesis through inhibition of $\mathrm{Wnt} / \beta$-catenin signaling pathway. Plos One 9: e107463, 2014.

14. Tamura K: Development of cell-cycle checkpoint therapy for solid tumors. Jpn J Clin Oncol 45: 1097-1192, 2015.

15. Gutschner T, Hämmerle M, Eissmann M, Hsu J, Kim Y, Hung G, Revenko A, Arun G, Stentrup M, Gross M, et al: The noncoding RNA MALAT1 is a critical regulator of the metastasis phenotype of lung cancer cells. Cancer Res 73: 1180-1189, 2013.

16. Rosanò L, Spinella F and Bagnato A: Endothelin 1 in cancer: Biological implications and therapeutic opportunities. Nat Rev Cancer 13: 637-651, 2013.

17. Fagan KA, McMurtry IF and Rodman DM: Role of endothelin-1 in lung disease. Respir Res 2: 90-101, 2001.

18. Fu L, Chen W, Guo W, Wang J, Tian Y, Shi D, Zhang X, Qiu H, Xiao X, Kang T, et al: Berberine targets AP-2/hTERT, NF- $x$ B/COX-2, HIF-1 $\alpha / \mathrm{VEGF}$ and cytochrome-c/caspase signaling to suppress human cancer cell growth. PLoS One 8: e69240, 2013. 
19. Lau MT, Klausen C and Leung PCK: E-cadherin inhibits tumor cell growth by suppressing PI3K/Akt signaling via $\beta$-cateninEgr1-mediated PTEN expression. Oncogene 30: 2753-2766, 2011.

20. Ridley AJ: RhoA, RhoB and RhoC have different roles in cancer cell migration. J Microsc 251: 242-249, 2013.

21. Patterson DM, Gao D, Trahan DN, Johnson BA, Ludwig A, Barbieri E, Chen Z, Diaz-Miron J, Vassilev L, Shohet JM and Kim ES: Effect of MDM2 and vascular endothelial growth factor inhibition on tumor angiogenesis and metastasis in neuroblastoma. Angiogenesis 14: 255-266, 2011.

22. Spinella F, Rosanò L, Di Castro V, Decandia S, Nicotra MR Natali PG and Bagnato A: Endothelin-1 and endothelin-3 promote invasive behavior via hypoxia-inducible factor-1alpha in human melanoma cells. Cancer Res 67: 1725-1734, 2007.

23. Matsuura A, Yamochi W, Hirata Ki, Kawashima S and Yokoyama M: Stimulatory interaction between vascular endothelial growth factor and endothelin-1 on each gene expression. Hypertension 32: 89-95, 1998.

24. Salani D, Di Castro V, Nicotra MR, Rosanò L, Tecce R, Venuti A, Natali PG and Bagnato A: Role of endothelin-1 in neovascularization of ovarian carcinoma. Am J Pathol 157: 1537-1547, 2000.

25. Rosanò L, Spinella F, Di Castro V, Nicotra MR, Dedhar S de Herreros AG, Natali PG and Bagnato A: Endothelin-1 promotes epithelial-to-mesenchymal transition in human ovarian cancer cells. Cancer Res 65: 11649-11657, 2005.

26. Xu G, Zhang W, Bertram P, Zheng XF and McLeod $\mathrm{H}$ : Pharmacogenomic profiling of the PI3K/PTEN-AKT-mTOR pathway in common human tumors. Int J Oncol 24: 893-900, 2004.

27. Beckner ME, Gobbel GT, Abounader R, Burovic F, Agostino NR, Laterra J and Pollack IF: Glycolytic glioma cells with active glycogen synthase are sensitive to PTEN and inhibitors of PI3K and gluconeogenesis. Lab Invest 85: 1457-1470, 2005.

28. Thomas WD, Zhang XD, Franco AV, Nguyen T and Hersey P: TNF-related apoptosis-inducing ligand-induced apoptosis of melanoma is associated with changes in mitochondrial membrane potential and perinuclear clustering of mitochondria J Immunol 165: 5612-5620, 2000

29. Ruth MC, Xu Y, Maxwell IH, Ahn NG, Norris DA and Shellman YG: RhoC promotes human melanoma invasion in a PI3K/Akt-dependent pathway. J Invest Dermatol 126: 862-868, 2006.

30. Blanco-Aparicio C, Pequeño B, Moneo V, Romero L, Leal JF, Velasco J, Fominaya J and Carnero A: Inhibition of phosphatidylinositol-3-kinase synergizes with gemcitabine in low-passage tumor cell lines correlating with Bax translocation to the mitochondria. Anti-Cancer Drug 16: 977-987, 2005.

31. Del Bufalo D, Di Castro V, Biroccio A, Varmi M, Salani D, Rosanò L, Trisciuoglio $\mathrm{D}$, Spinella $\mathrm{F}$ and Bagnato $\mathrm{A}$ : Endothelin-1 protects ovarian carcinoma cells against paclitaxel-induced apoptosis: Requirement for Akt activation. Mol Pharmacol 61: 524-532, 2002.

32. Leahy KM, Ornberg RL, Wang Y, Zweifel BS, Koki AT and Masferrer JL: Cyclooxygenase-2 inhibition by celecoxib reduces proliferation and induces apoptosis in angiogenic endothelial cells in vivo. Cancer Res 62: 625-631, 2002.

33. Hsieh HL, Sun CC, Wang TS and Yang CM: PKC-delta/ c-Src-mediated EGF receptor transactivation regulates thrombin-induced COX-2 expression and PGE(2) production in rat vascular smooth muscle cells. Biochim Biophys Acta 1783: $1563-1575,2008$

34. Appleby SB, Ristimäki A, Neilson K, Narko K and Hla T: Structure of the human cyclo-oxygenase-2 gene. Biochem J 302: 723-727, 1994.

35. Morita I, Schindler M, Regier MK, Otto JC, Hori T, DeWitt DL and Smith WL: Different intracellular locations for prostaglandin endoperoxide H synthase-1 and -2. J Biol Chem 270: 10902-10908, 1995.

36. Murata H, Kawano S, Tsuji S, Tsuji M, Sawaoka H, Kimura Y, Shiozaki H and Hori M: Cyclooxygenase-2 overexpression enhances lymphatic invasion and metastasis in human gastric carcinoma. Am J Gastroenterol 94: 451-455, 1999.
37. Narumiya S, Tanji M and Ishizaki T: Rho signaling, ROCK and mDia1, in transformation, metastasis and invasion. Cancer Metastasis Rev 28: 65-76, 2009.

38. Wong CM and $\mathrm{Ng}$ IO: Molecular pathogenesis of hepatocellular carcinoma. Liver Int 28: 160-174, 2008.

39. Wang M, Wang XJ and Liu BR: Effect of shRNA targeted against RhoA on proliferation and migration of human colonic cancer cells. Int J Clin Exp Pathol 8: 7040-7044, 2015.

40. He X, Qian Y, Cai H and Wang Z: The effect of RhoC siRNA on the invasiveness and proliferation of human cervical cancer cell line SiHa cells. J Huazhong Univ Sci Technolog Med Sci 28: 665-669, 2008

41. Hakem A, Sanchez-Sweatman O, You-Ten A, Duncan G, Wakeham A, Khokha R and Mak TW: RhoC is dispensable for embryogenesis and tumor initiation but essential for metastasis. Genes Dev 19: 1974-1999, 2005.

42. Li NF, Gemenetzidis E, Marshall FJ, Davies D, Yu Y, Frese K, Froeling FE, Woolf AK, Feakins RM, Naito Y, et al: RhoC interacts with integrin $\alpha 5 \beta 1$ and enhances its trafficking in migrating pancreatic carcinoma cells. PLoS One 8: 0e81575, 2013.

43. Kleer CG, van Golen KL, Zhang Y, Wu ZF, Rubin MA and Merajver SD: Characterization of RhoC expression in benign and malignant breast disease: a potential new marker for small breast carcinomas with metastatic ability. Am J Pathol 160: 579-584, 2002.

44. Pillé JY, Denoyelle C, Varet J, Bertrand JR, Soria J, Opolon P, Lu H, Pritchard LL, Vannier JP, Malvy C, et al: Anti-RhoA and anti-RhoC siRNAs inhibit the proliferation and invasiveness of MDA-MB-231 breast cancer cells in vitro and in vivo. Mol Ther 11: 267-274, 2005.

45. Yu YF, Zhang Y, Shen N, Zhang RY and Lu XQ: Effect of VEGF, P53 and telomerase on angiogenesis of gastric carcinoma tissue. Asian Pac J Trop Med 7: 293-296, 2014.

46. van Golen KL, Wu ZF, Qiao XT, Bao L and Merajver SD: RhoC GTPase overexpression modulates induction of angiogenic factors in breast cells. Neoplasia 2: 418-425, 2000.

47. Fukata $M$ and Kaibuchi K: Rho-family GTPases in cadherin-mediated cell-cell adhesion. Nat Rev Mol Cell Bio 2: 887-897, 2001.

48. Kidera Y, Tsubaki M, Yamazoe Y, Shoji K, Nakamura H, Ogaki M, Satou T, Itoh T, Isozaki M, Kaneko J, et al: Reduction of lung metastasis, cell invasion, and adhesion in mouse melanoma by statin-induced blockade of the Rho/Rho-associated coiledcoil-containing protein kinase pathway. J Exp Clin Cancer Res 29: 127, 2010.

49. Bernard A, Gao-Li J, Franco CA, Bouceba T, Huet A and $\mathrm{Li} \mathrm{Z}$ : Laminin receptor involvement in the anti-angiogenic activity of pigment epithelium-derived factor. J Biol Chem 284: 10480-10490, 2009.

50. Mahtabifard A, Merritt RE, Yamada RE, Crystal RG and Korst RJ: In vivo gene transfer of pigment epithelium-derived factor inhibits tumor growth in syngeneic murine models of thoracic malignancies. J Thorac Cardiov Surg 126: 28-38, 2003.

51. Takenaka K, Yamagishi S, Jinnouchi Y, Nakamura K, Matsui T and Imaizumi T: Pigment epithelium-derived factor (PEDF)-induced apoptosis and inhibition of vascular endothelial grow th factor (VEGF) expression in MG63 human osteosarcoma cells. Life Sci 77: 3231-3241, 2005.

52. Zhang L, Chen J, Ke Y, Mansel RE and Jiang WG: Expression of pigment epithelial derived factor is reduced in non-small cell lung cancer and is linked to clinical outcome. Int J Mol Med 17: 937-944, 2006

53. Huang X, Chen L, Fu G, Xu H and Zhang X: Decreased expression of pigment epithelium-derived factor and increased microvascular density in ovarian endometriotic lesions in women with endometriosis. Eur J Obstet Gynecol Reprod Biol 165: 104-109, 2012

54. Chen J, Ye L, Zhang L and Jiang WG: The molecular impact of pigment epithelium-derived factor, PEDF, on lung cancer cells and the clinical significance. Int J Oncol 35: 159-166, 2009.

55. Abe R, Fujita Y and Yamagishi S: Angiogenesis and metastasis inhibitors for the treatment of malignant melanoma. Mini Rey Med Chem 7: 649-661, 2007. 